Sādhanā Vol. 40, Part 7, October 2015, pp. 2253-2261. (C) Indian Academy of Sciences

\title{
Flow hydrodynamics near inlet key of Piano Key Weir (PKW)
}

\author{
HARINARAYAN TIWARI* and NAYAN SHARMA
}

Department of Water Resources Development and Management, Indian Institute of Technology Roorkee, Roorkee 247667, India

e-mail: haribit31@gmail.com; haribit31@outlook.com

MS received 6 November 2014; revised 29 May 2015; accepted 1 July 2015

\begin{abstract}
This paper presents fundamental outcomes from an experimental study on the hydrodynamic performance near inlet key of Piano Key Weir (PKW). Hydrodynamic performance was tested in a circulated open channel that comprised of PKW and sand bed $\left(\mathrm{d}_{50}=0.25 \mathrm{~mm}\right)$. Instantaneous velocities were measured at 20 cross sections using Laser Doppler Velocimeter (LDV) with constant discharge and depth. Average velocity and turbulence intensities in both directions were investigated. Average longitudinal velocities are found very much consistent at every point and maximum around the midway of inlet key. In transverse direction, flow is bifurcating in two directions which are also confirmed by average transverse velocity estimation. Variation of turbulence intensity presents average 10 times higher transverse turbulence than longitudinal turbulence near inlet key of PKW.
\end{abstract}

Keywords. Piano Key Weir; hydrodynamic; river; turbulence; LDV.

\section{Introduction}

Thoughtful learning of flow behavior in the upstream and downstream of hydraulic structures facilitates in their appropriate design, continuation and planning. Piano Key Weir, an alternative hydraulic structure with high discharge capacity has two important components: Inlet Key and Outlet Key (Dewals et al 2012; Leite Ribeiro et al 2011; Lempérière \& Ouamane 2003; Lux 1993; Machiels et al 2011; Nayan Sharma 2007). Inlet key is the important component of PKW that can affect the characteristics of flow behavior in the upstream of the weir (Anderson \& Tullis 2011; Kabiri-Samani \& Javaheri 2012; Machiels et al 2011; Ribeiro et al 2012). Flow behavior is complicated to envisage in a channel near any hydraulic structures until small scale time fluctuating nature of flows is clearly understood with the help of advanced instrumentation and computing technology (Grass 1971; Hino et al 1983; Hoyas \& Jiménez 2006; Nikora et al 1998). Laser Doppler Velocimeter is mainly striking instrument for use in channel flow as no calibration is essential and flow field is not disturbed by the probe intervention (Byun et al 2004;

${ }^{*}$ For correspondence 
Nezu 2005; Voulgaris \& Trowbridge 1998). Velocity and turbulence behavior in front of inlet key of PKW using LDV is the objective of this paper.

\section{Piano Key Weir}

A Piano Key Weir is a kind of labyrinth hydraulic structure in general placed transversely to rivers that causes flow discontinuity and affects hydraulics of rivers (Erpicum et al 2011; Laugier et al 2012; Ouamane 2013a). General transverse structures like weir (triangular or rectangular) have a significant function to maintain upstream depth of water and securing water resources for optimum use (Lempérière \& Ouamane 2003; Lempérière et al 2011; Nayan Sharma \& Tiwari 2013; Ouamane 2013b; Ribeiro et al 2013; Sharma et al 2012). However, it destabilizes sediment continuity because flow velocity reduced due to the increased water depth (Bai \& Duan 2014; Fan \& Morris 1992). Due to the restricting way of sediment downstream, it is deposited directly upstream of a weir (Kim et al 2014; Kondolf et al 2014). Four types of Piano Key Weir are classified in literature (table 1) based on their type of inlet and outlet key (Ribeiro et al 2012). Type A of PKW is the mostly used PKW in the field across the world.

As sediment from upstream normally moves downstream by flowing water, geographical features are changed and hydro-ecological habitats are subsequently affected. Inhibited sediment continuity has an effect on the hydro-environmental status downstream of a weir, which can result in serious disturbance to the riparian ecosystem (Kim et al 2014). To support recovery of sediment continuity in rivers, the Piano Key Weir might be used as an alternative transverse structure. It needs the elemental study turbulence phenomenon near PKW to point out the sed-

Table 1. Type of Piano Key Weir.

Type of PKW
PKW C
Inlet side over hanged
NKW D


Table 2. Detailed of Piano Key Weir.

\begin{tabular}{lc}
\hline PKW component & Dimension $(\mathrm{mm})$ \\
\hline Inlet & 120 \\
Outlet & 120 \\
Divide wall & 15 \\
Side wall & 7.5 \\
Input ramp slope & $\tan ^{-1}(1 / 3)$ \\
Output ramp slope & $\tan ^{-1}(1 / 2)$ \\
Height of Weir & 180 \\
\hline
\end{tabular}

iment transport (Sharma et al 2012). Since the inlet key has great role in sediment movement upstream, elemental study of velocity and turbulence behavior is required. Due to high sediment discharge in Indian rivers, Type C (where the upstream obstruction is less) might be more useful. By realizing the significance of key, in this study an inlet key of PKW ' $\mathrm{C}$ ' was virtually divided into 20 parts at the height of crest level. Flow division phenomenon was observed and analyzed. Dimensional details of PKW were presented in table 2. Slope of inlet key was kept flatter with respect to outlet key. Triangular piers are also provided (figure 1) to support structure as well as smoothly bifurcate the flow.

\section{Experimental setup}

The experiments were conducted in River Engineering Laboratory, Water Resources Development and Management Department, Indian Institute of Technology Roorkee, India. An experimental program was established to quantify the flow behavior at crest level inlet key of

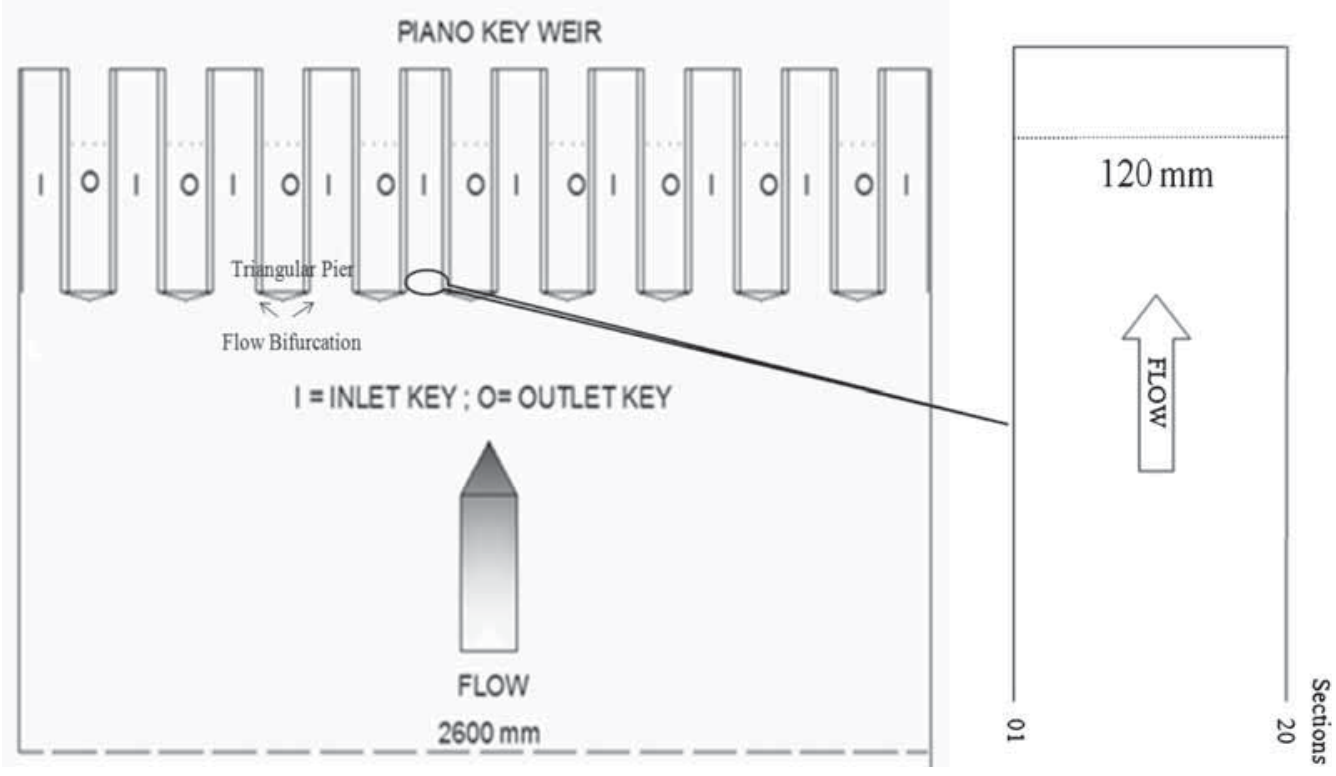

Figure 1. Detailed plan of experiment. 
weir in an open channel flow. The flume width, height and length are $2600 \mathrm{~mm}, 1000 \mathrm{~mm}$ and $20 \mathrm{~m}$, respectively. In the experiment, velocity at different 20 horizontal points located $5 \mathrm{~cm}$ in front to tip of PKW was taken (figure 1).

LDV is device which is used for measuring the velocities of moving test specimens employing a laser beam source. It is a well established flow measurement technique that is capable of providing high quality, high-spatial resolution data over a range of flow conditions (Penney 1969; Stein \& Pfeifer 1969; Yeh \& Cummins 1964). After the 50 years of first use numerous modifications have taken place making it the standard in velocity measurement in fluid flow (Yeh \& Cummins 1964). LDV may estimate multi-ordered velocity moments precisely within the large dynamic range. LDV is one of the leading single point measurement techniques apart from seeding particle limitation. It is the non-contact type instrument with $\pm 0.2 \%$ of mean velocity error and low sample volume of $0.008 \mathrm{~mm}^{3}$. This system relies upon the measurement of the Doppler frequency shift of light scattered from an illuminating laser beam by particles entrained within the flow. It has also been widely used for open channel laboratory turbulence measurements (Ali et al 2013; Buchhave et al 1979; Nakagawa \& Nezu 1987; Nezu \& Rodi 1986; Nezu \& Sanjou 2011; Tachie et al 2000; Tominaga \& Nezu 1991)(figure 2).

A two-dimensional LDV system (TSI Inc.) powered by an Argon Ion laser (15 Watts maximum CW multiline output) was used for velocity measurements. The particle movement creates Doppler shift in the light frequency and is directly proportional to its velocity. Measurement

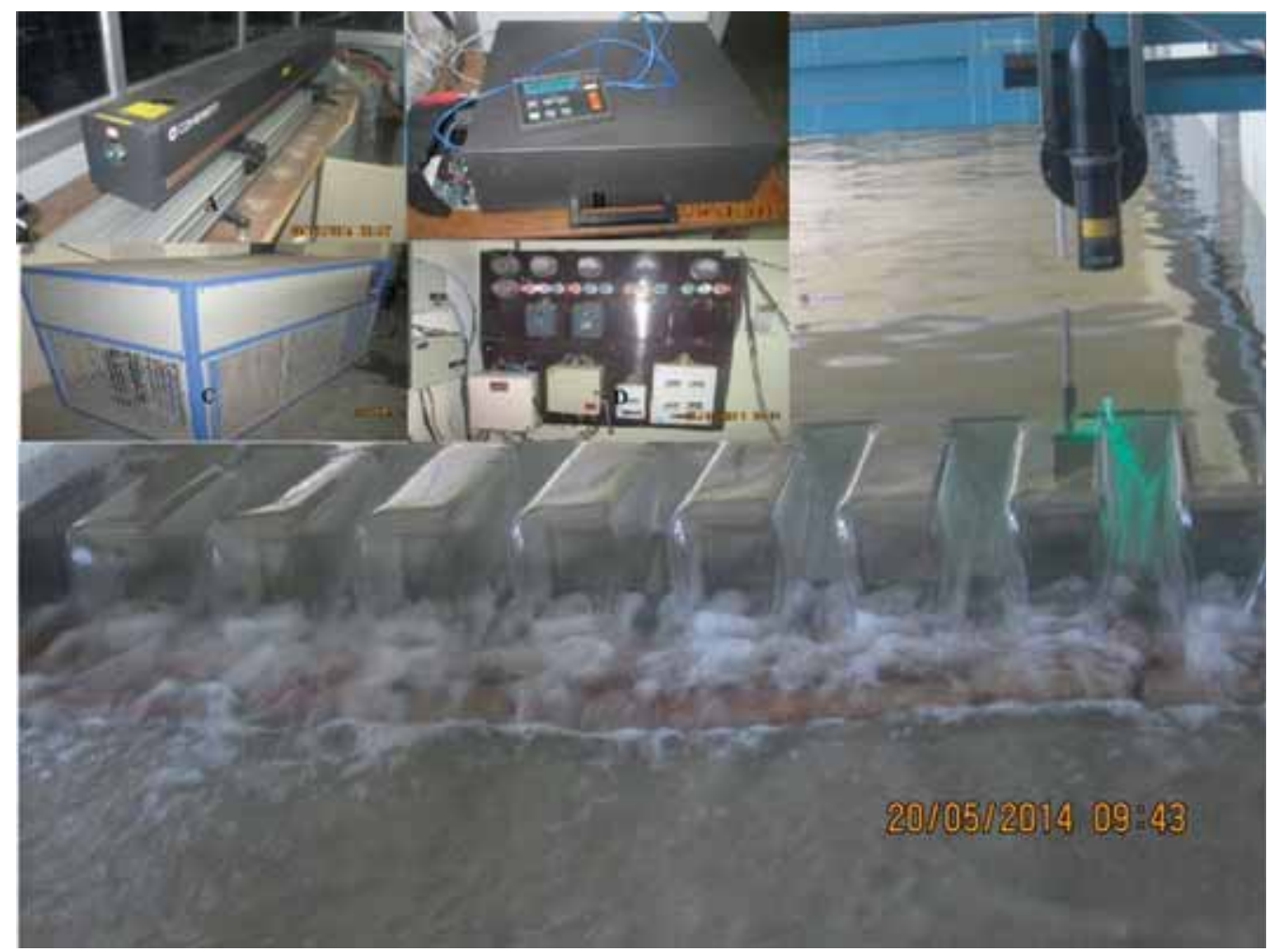

Figure 2. Lab arrangement of PKW with LDV (A) Laser beam source, (B) CPU of LDV, (C) Chiller used for cooling LDV, (D) 3-Phase electrical arrangement for LDV. 
of Doppler shift frequency of a measurement of particles velocity. Assuming particle size very small, fluid velocity can be equated as particle velocity. Data acquired by LDV system form the required locations (figure 1) was processed through FLOWSIZER ${ }^{\mathrm{TM}}$.

\section{Results and discussions}

Experiments with LDV arrangements figure 2 were carried out on PMT voltage $400 \mathrm{~V}$, Burst Threshold $50 \mathrm{mV}$ and medium SNR. Two thousands coincidence particles were taken for this study. Coincidence particle mode in LDV facilitates taking velocity of the same particle in both directions at same time, which will lead to less chance of error. Instantaneous velocity at cross section one was shown in figure 3. Spikes of the data were removed using acceleration threshold method at $1.5 \mathrm{~g}$. Average of corrected data set of each point in longitudinal and transverse direction was evaluated (figure 4).

Extending this evaluation, we compared the average longitudinal velocity and average transverse velocity for each of the sampled sections, and found that trends follow the feature of hydraulic structure. These measurements indicate that maximum average longitudinal velocity at midway of inlet key and change in sign for average transverse velocity indicates the effect of inlet key in the flow. This fact can be useful for mixing as well as transportation of sediment in the upstream of PKW.

The falling trend of transverse velocity seemed to be linked with a characteristic of liquidsolid interactions in attracting flows near sharp edged overflow weir. In the mid of the flow effect of solid edges is getting reduced and reversed at the point where another side of weir comes into role. Lower overall uncertainty $(7 \mathrm{~mm} / \mathrm{s})$ was established in the case of longitudinal velocity. Similarly, for the transverse velocity (where key's divide wall acts as sharp created weir) higher

Instantaneous longitudinal velocity _ Instantaneous transverse velocity

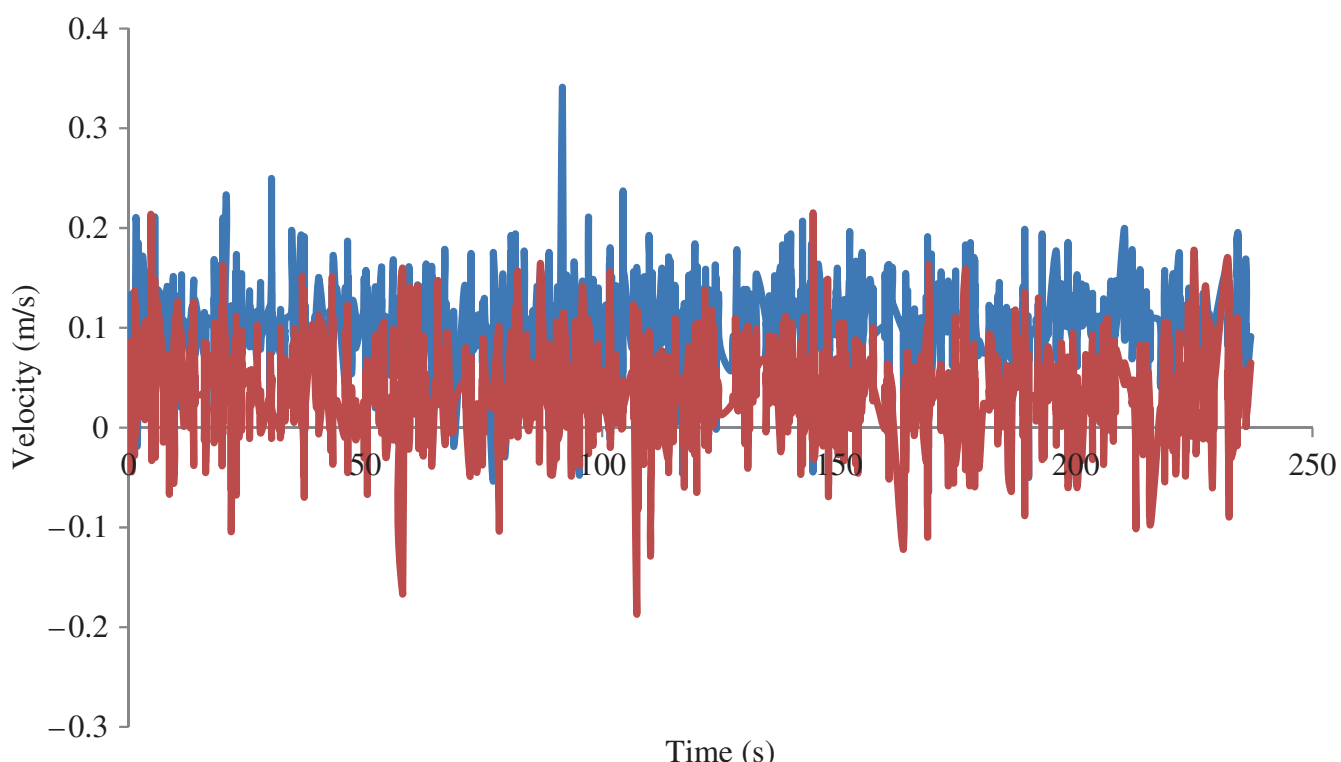

Figure 3. Instantaneous velocities at cross section 1. 


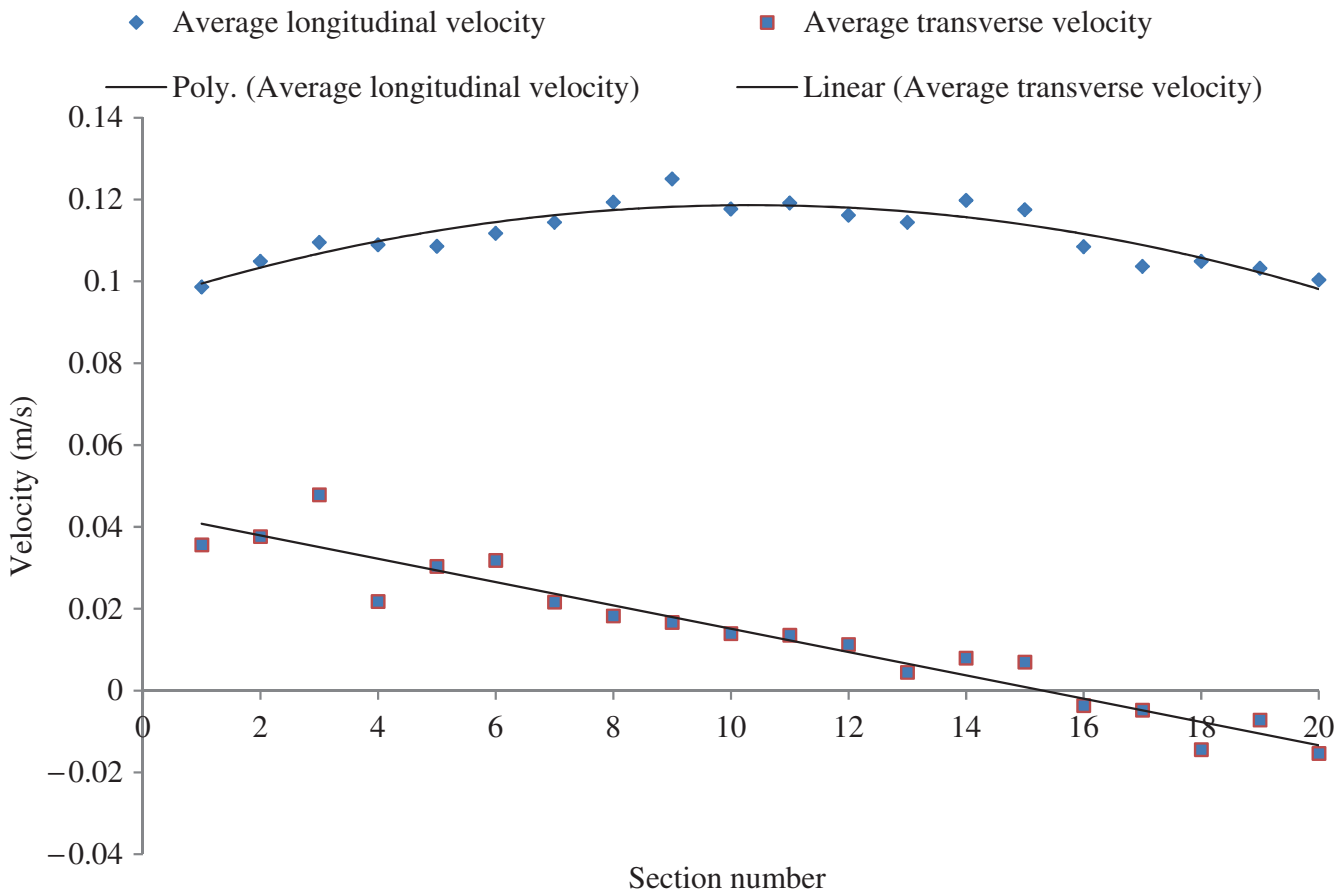

Figure 4. Average velocities (longitudinal and transverse).

uncertainty $(17 \mathrm{~mm} / \mathrm{s})$ was evaluated. To broaden this result into stochastic physics, turbulent intensity has been estimated using available fluctuating data.

Turbulent intensity is basically defined as the ratio root mean square velocity to the mean velocity (Eq. 1).

$$
\% T I=\frac{R M S \text { velocity }}{\text { Mean velocity }} \times 100 .
$$

Table 3. Turbulence intensity.

\begin{tabular}{lccccc}
\hline Sections & $\begin{array}{c}\text { Average } \\
\text { longitudinal } \\
\text { turbulence } \\
\text { intensity (\%) }\end{array}$ & $\begin{array}{c}\text { Average } \\
\text { transverse } \\
\text { turbulence } \\
\text { intensity (\%) }\end{array}$ & Sections & $\begin{array}{c}\text { Average } \\
\text { longitudinal } \\
\text { turbulence } \\
\text { intensity (\%) }\end{array}$ & $\begin{array}{c}\text { Average } \\
\text { transverse } \\
\text { turbulence } \\
\text { intensity (\%) }\end{array}$ \\
\hline 1 & 35.3 & 103.2 & 11 & 29.8 & 261.3 \\
2 & 32.9 & 96.9 & 12 & 28.1 & 371.6 \\
3 & 28.1 & 86.0 & 13 & 28.5 & 907.7 \\
4 & 31.6 & 174.9 & 14 & 25.2 & 483.5 \\
5 & 28.3 & 120.4 & 15 & 27.9 & 503.8 \\
6 & 28.9 & 101.6 & 16 & 30.0 & 963.5 \\
7 & 28.5 & 165.3 & 17 & 33.2 & 728.8 \\
8 & 26.9 & 205.7 & 18 & 33.0 & 269.6 \\
9 & 27.9 & 205.7 & 19 & 29.2 & 507.2 \\
10 & 25.8 & 277.0 & 20 & 32.3 & 234.4 \\
\hline
\end{tabular}


Table 3 reports the responses velocity fluctuation in terms of turbulence intensity (\%) estimated by FLOWSIZER ${ }^{\mathrm{TM}}$. The percentage of turbulence intensity (longitudinal) for all experiments lies in between very short range (25.2-35.3) with $2.67 \%$ of standard deviation. The same feature of turbulence intensity was reported (transverse) with minimum $86 \%$ to maximum $963.5 \%$ with standard deviation of $265.9 \%$. It indicates that turbulence production due to PKW in stream flow direction is far less in comparison with transverse flow. From the observations it can be easily read out that productions of maximum turbulence in both (longitudinal \& transverse) directions are not in the same pattern. It corresponds that action of maximum or minimum longitudinal turbulence location is not the same as transverse turbulence.

\section{Conclusions}

The average velocity and turbulent intensities near inlet key, in both directions (longitudinal and transverse), were investigated in a steady open channel flow with PKW. Twenty cross sections were tested, at the same discharge depth condition. All runs had the same PMT and threshold voltage of LDV. The coincidence mode was chosen for better results of instantaneous velocities as it takes same particles at same instant. Results show that the longitudinal and transverse have different hydrodynamic behaviors (velocities and turbulent intensities). Minor differences are observed at average longitudinal quantities and major in average transverse quantities. These differences may be attributable to the presence of inlet key in transverse and the flow modification that this generates. The main contribution of this research is to demark entirely dissimilar behavior of both (longitudinal and transverse) velocity components and turbulence intensity. Turbulent intensity (which is linked with dynamic pressure as well as mechanism of entrainment in the flow) is characterized in this study. To pursue the higher hydraulic stability of outlet key (receiver of water form inlet key) characteristics behavior of inlet key is essentially required. Higher turbulence intensity might be reduced using different shapes of key, which may be taken as the scope of future research. The present work also provides a fundamental data set that will serve as an initiation for further research under different flow and structural conditions and/or to validate numerical models concerned with the design and construction of PKW.

\section{Acknowledgements}

The authors are grateful to Department of Water Resources Development and Management, Indian Institute of Technology Roorkee, India. They are also thankful to the Ministry of Human Resource Development, Government of India for their regular fellowship to conduct research.

\section{References}

Ali S, Ghani U and Latif A 2013 Study of turbulent kinetic energy and reattachment length downstream the obstruction in an open channel. Life Sci. J. 10(10s)

Anderson R and Tullis B 2011 Comparison of piano key and rectangular labyrinth weir hydraulics. $J$. Hydraulic Eng. 138(4): 358-361

Bai Y and Duan J G 2014 Simulating unsteady flow and sediment transport in vegetated channel network. J. Hydrol. 515: 90-102

Buchhave P, George W K and Lumley J L 1979 The measurement of turbulence with the laser-Doppler anemometer. Ann. Rev. Fluid Mech. 11(1): 443-503

Byun G, Ölçmen S M and Simpson R L 2004 A miniature laser-Doppler velocimeter for simultaneous three-velocity-component measurements. Measur. Sci. Technol. 15(10): 2075 
Dewals B, Erpicum S, Archambeau P and Pirotton M 2012 Experimental study of velocity fields in rectangular shallow reservoirs. J. Hydraulic Res. 50(4): 435-436

Erpicum S, Nagel V and Laugier F 2011 Piano Key Weir design study at Raviege dam. Labyrinth and Piano Key Weirs-PKW 2011

Fan J and Morris G L 1992 Reservoir sedimentation. I: Delta and density current deposits. J. Hydraulic Eng. 118(3): 354-369

Grass A 1971 Structural features of turbulent flow over smooth and rough boundaries. J. Fluid Mech. 50(02): 233-255

Hino M, Kashiwayanagi M, Nakayama A and Hara T 1983 Experiments on the turbulence statistics and the structure of a reciprocating oscillatory flow. J. Fluid Mech. 131: 363-400

Hoyas S and Jiménez J 2006 Scaling of the velocity fluctuations in turbulent channels up to $\operatorname{Re} \tau=$ 2003. Phys. Fluids (1994-present) 18(1): 011702

Kabiri-Samani A and Javaheri A 2012 Discharge coefficients for free and submerged flow over Piano Key weirs. J. Hydraulic Res. 50(1): 114-120

Kim S, Im J and Lee S O 2014 Assessment of sediment exclusion efficiency for several modified Labyrinth weirs. Paddy Water Environ.1-8

Kondolf G M, Gao Y, Annandale G W, Morris G L, Jiang E, Zhang J and Guo Q 2014 Sustainable sediment management in reservoirs and regulated rivers: Experiences from five continents. Earth's Future 2(5): 256-280

Laugier F, Vermeulen J and Pralong J 2012 Achievement of new innovative labyrinth Piano Key Weir Spillways (PKW). In: proceedings of piano Key weir for in-stream storage and dam safety (pKwIsD2012), New Delhi. New Delhi, India 25-42

Leite Ribeiro M, Bieri M, Boillat J-L, Schleiss A, Singhal G and Sharma N 2011 Discharge capacity of piano key weirs. J. Hydraulic Eng. 138(2): 199-203

Lempérière F and Ouamane A 2003 The Piano Keys weir: a new cost-effective solution for spillways. Int. J. Hydropower Dams 10(5): 144-149

Lempérière F, Vigny J and Ouamane A 2011 General comments on Labyrinth and Piano Key Weirs: The past and present. Paper presented at the Proceedings International Conference Labyrinth and Piano Key Weirs Liège B

Lux F 1993 Design methodologies for labyrinth weirs. Paper presented at the Internatioinal conference on Hydropower, Water Power Nashville, Tennessee, USA

Machiels O, Erpicum S, Dewals B J, Archambeau P and Pirotton M 2011 Experimental observation of flow characteristics over a Piano Key Weir. J. Hydraulic Res. 49(3): 359-366

Nakagawa H and Nezu I 1987 Experimental investigation on turbulent structure of backward-facing step flow in an open channel. J. Hydraulic Res. 25(1): 67-88

Nayan Sharma G S 2007 The Piano Key Weir: A new dam safety solution for enhanced spillway capacity. Paper presented at the Annual Conference of the Association of State Dam Safety Officials, Austin, Texas, USA

Nayan Sharma and Tiwari H 2013 Experimental study on vertical velocity and submergence depth near Piano Key weir. Labyrinth and Piano Key Weirs II, pp. 93-100

Nezu I 2005 Open-channel flow turbulence and its research prospect in the 21 st century. J. Hydraulic Eng. 131(4): 229-246

Nezu I and Rodi W 1986 Open-channel flow measurements with a laser Doppler anemometer. J. Hydraulic Eng. 112(5): 335-355

Nezu I and Sanjou M 2011 PIV and PTV measurements in hydro-sciences with focus on turbulent openchannel flows. J. Hydro-Environment Res. 5(4): 215-230

Nikora V I, Goring D G and Biggs B J 1998 On gravel-bed roughness characterization. Water Resources Res. 34(3): 517-527

Ouamane A 2013a Improvement of labyrinth weirs shape. Paper presented at the Labyrinth and Piano KeyWeirs II - PKW 2013, Paris

Ouamane A 2013b Improvement of labyrinth weirs shape. Labyrinth and Piano Key Weirs II, 15

Penney C 1969 Differential Doppler velocity measurements. IEEE J. Quantum Electron. 5(6): 318-318 
Ribeiro M L, Pfister M and Schleiss A J 2013 Overview of Piano Key weir prototypes and scientific model investigations. Labyrinth and Piano Key Weirs II, 273

Ribeiro M L, Pfister M, Schleiss A J and Boillat J-L 2012 Hydraulic design of A-type Piano Key weirs. J. Hydraulic Res. 50(4): 400-408

Sharma N, Tiwari H and Singhal G D 2012 Piano-Key Weir Technology: A possible solution of Dam safety in narrow river and existing dams. Paper presented at the Dams and Spillways in Himalayan Regions

Stein H D v and Pfeifer H J 1969 A doppler difference method for velocity measurements. Metrologia 5(2): 59

Tachie M, Bergstrom D and Balachandar R 2000 Rough wall turbulent boundary layers in shallow open channel flow. J. Fluids Eng. 122(3): 533-541

Tominaga A and Nezu I 1991 Turbulent structure in compound open-channel flows. J. Hydraulic Eng. 117(1): 21-41

Voulgaris G and Trowbridge J H 1998 Evaluation of the acoustic Doppler velocimeter (ADV) for turbulence measurements. J. Atmos. Oceanic Technol. 15(1): 272

Yeh Y and Cummins H 1964 Localized fluid flow measurements with an He-Ne laser spectrometer. Appl. Phys. Lett. 4(10): 176-178 